\title{
Infantile Neurodegeneration and Hair Changes: A Rare Case of Menkes Disease
}

\author{
Nikhil Vikas Pawar ${ }^{a}$ Fatima Farid Mir ${ }^{b}$ \\ aPediatric Neurology Department, Latifa Women and Children Hospital, Dubai, United Arab Emirates; \\ bediatrics Department, Latifa Women and Children Hospital, Dubai, United Arab Emirates
}

\section{Keywords}

Menkes disease $\cdot$ Copper storage disease

\begin{abstract}
A 4-month-old, previously healthy boy presented with acute onset of prolonged, recurrent seizure activity followed by neurodevelopmental deterioration and concurrent hair shaft hypopigmentation with fragility. Initial evaluation revealed significant low serum copper and ceruloplasmin, electrical status epilepticus on electroencephalography, and generalized subcortical white matter changes with diffuse tortuosity of intracranial vessels on MRI brain. In addition, a genetic study with whole-genome sequencing demonstrated a hemizygous pathogenic variant at c.2179G >A $\mathrm{p}$ (Gly727Arg) on ATP7A, thereby confirming the diagnosis of Menkes disease. Symptomatic treatment with antiepileptic medications was provided along with an urgent referral to an advanced center for multidisciplinary care and copper histidine replacement therapy. @ 2022 The Author(s).

Published by S. Karger AG, Basel
\end{abstract}

\section{Introduction}

Menkes disease is a lethal neurodegenerative disorder due to defective ATP7A gene function. A perturbation in copper metabolism leads to failure of dependent cellular enzyme function and subsequent multisystem disease.
The inheritance pattern is X-linked recessive; however, approximately one-third of affected males have a negative family history [1], and recent studies have demonstrated carrier female disease phenotype [2]. Onset is in early infancy with relentless deterioration and an early demise by 3 years of age. Response to copper histidine is guarded and heavily dependent on the timing of therapy. We report a prototypal case of severe Menkes disease with genetically proven ATP7A defect.

\section{Case Report}

A previously healthy 4-month-old boy presented with a 2-week history of prolonged and recurrent seizures. The infant was a product of nonconsanguineous marriage, delivered at term via normal vaginal delivery with a birth weight of $2.7 \mathrm{~kg}$. The postnatal period was remarkable for neonatal sepsis, otherwise uneventful. There was negative family history for seizures or developmental delay.

After routine 4-month immunization, the infant developed epilepsy and neurodevelopmental deterioration, with concurrent hair fragility and hypopigmentation. Physical examination revealed normal head circumference and anterior fontanelle with frontal prominence and sparse, hypopigmented, kinky scalp hair (Fig. 1). Neurological examination showed visual inattention, mild axial and limb hypotonia, and brisk reflexes without any neurocutaneous signs. Systemic examination was within normal limits.

His prolonged complex seizure required admission and management with antiepileptic drugs (levetiracetam and topiramate). EEG showed features suggestive of electrical status epilepticus with bilateral centrotemporal epileptiform activities (more prominent on the right side) (Fig. 2). MRI brain revealed T2 hyperintensities karger@karger.com www.karger.com/dmj

Karger $\stackrel{\text { ' }}{=}$

GOPEN ACCESS
(C) 2022 The Author(s)

Published by S. Karger AG, Basel

This is an Open Access article licensed under the Creative Commons Attribution-NonCommercial-4.0 International License (CC BY-NC) (http://www.karger.com/Services/OpenAccessLicense), applicable to the online version of the article only. Usage and distribution for commercial purposes requires written permission.
Correspondence to:

Nikhil Vikas Pawar, dr.nikhilpawar@gmail.com 
of white matter in the bilateral temporoparietal region suggestive of gliosis along with cortical atrophy and extradural hydrocephalus (Fig. 3, 4). With a clinical suspicion of a genetic metabolic defect, focused investigations were sought, and subsequent reports were highly suggestive of the underlying Menkes disease (Table 1).

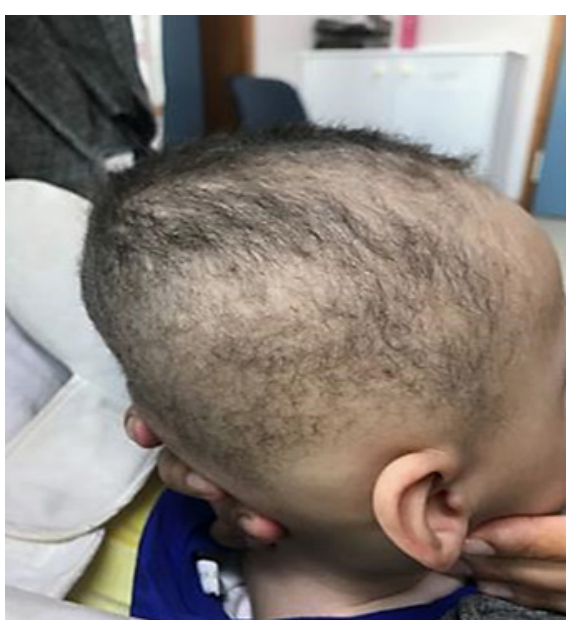

Fig. 1. Short, coarse, hypopigmented, brittle, and twisted hair.
The patient attained seizure freedom by 6 months of age; however, he relapsed once his mother tapered medications. In light of the above, the child traveled abroad for genetic investigations. Whole-genome sequencing revealed a hemizygous pathogenic variant at c.2179G >A p.(Gly727Arg) on ATP7A while the mother carried a novel pathogenic heterozygous variant c.2179G $>A$ $\mathrm{p}$ (Gly727Arg) in the ATP7A gene, consistent with the diagnosis of Menkes disease.

The Pediatric Neurologist reviewed the child; rehabilitation and home-based physiotherapy were recommended. Urgent referral was made to a center with higher specialization for multidisciplinary care and copper histidine replacement therapy.

\section{Discussion}

Copper is an essential element involved in cellular health. It is the third most abundant element in the body after iron and zinc, and its delicate homeostasis is crucial for preserving normal bodily functions, particularly neurologic and connective tissues [3]. Among the 2 most well-recognized disorders of copper metabolism is Menkes disease, arising due to copper deficiency, and Wilson disease, a consequence of copper toxicity.

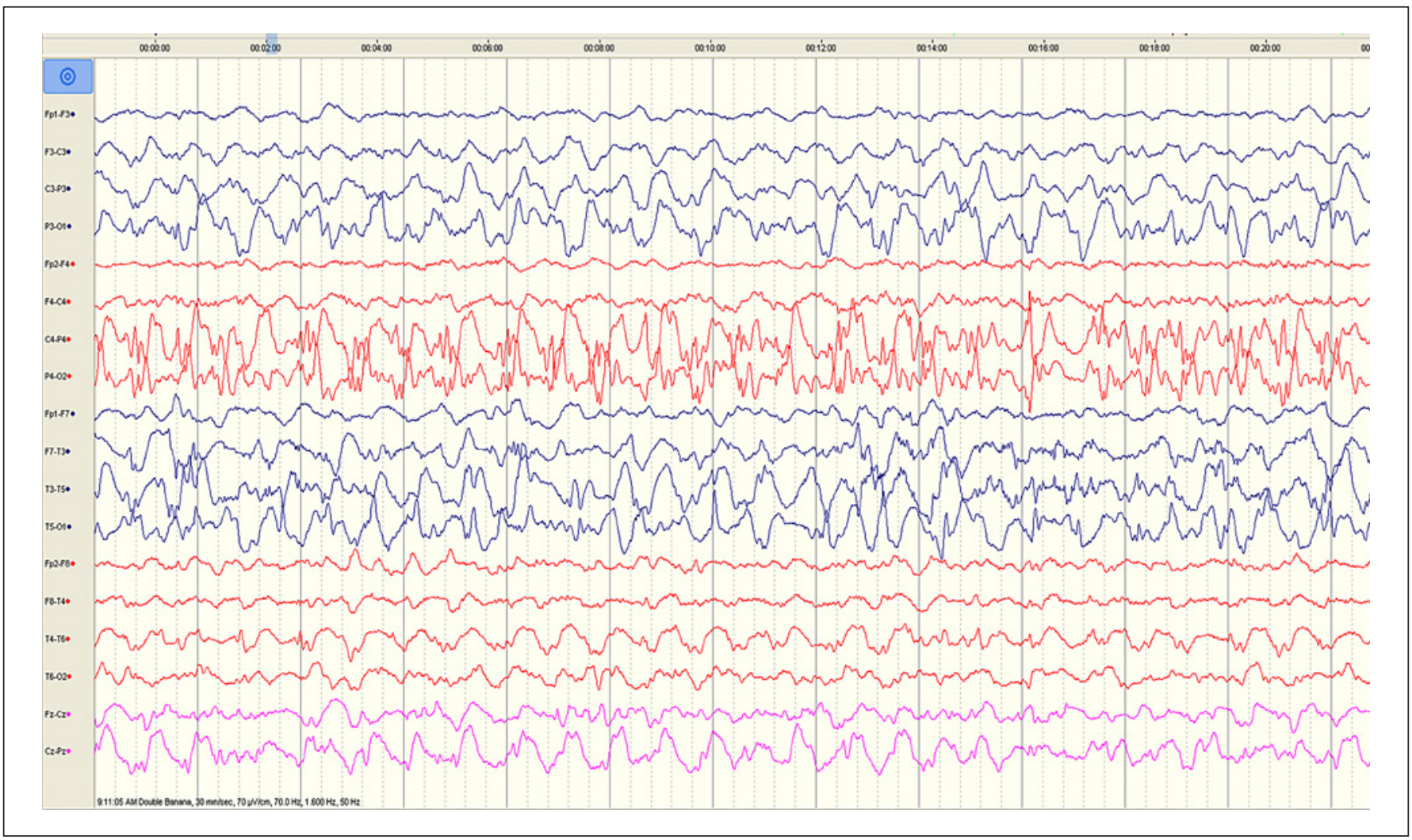

Fig. 2. EEG features suggestive of electrical status epilepticus with bilateral centrotemporal epileptiform activities (more prominent on the right side). 


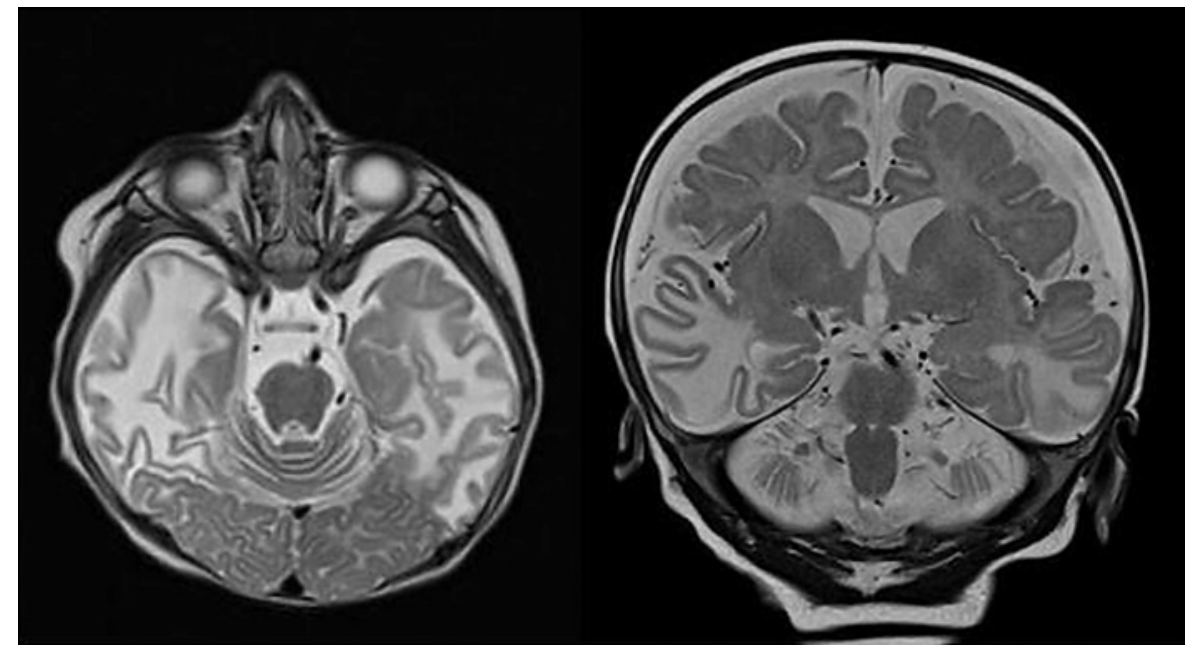

Fig. 3. Diffuse subcortical white matter signal changes in the bilateral temporoparietal regions suggestive of gliosis with hypointense signal in T1 and FLAIR images with hyperintense signal in T2 with no restricted diffusion or blooming artifacts.

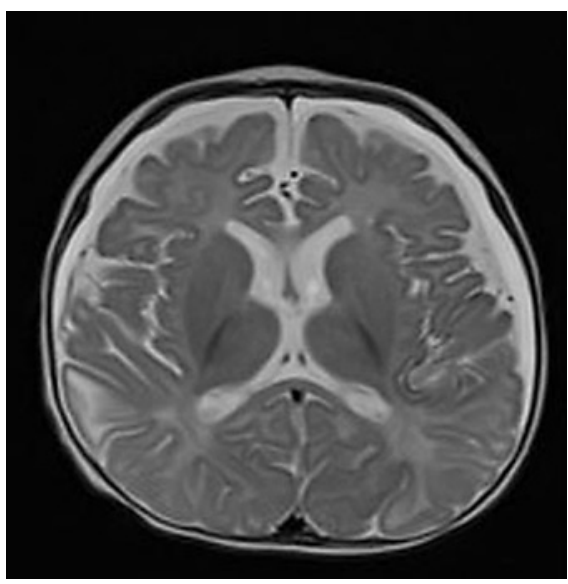

Fig. 4. Cortical atrophy and extra-axial hydrocephalus.

Table 1. Laboratory investigations

\begin{tabular}{ll}
\hline Test & Patient result \\
\hline FBC & Normal \\
Urea electrolytes & Normal \\
Liver function test & Normal \\
Serum copper & $24 \mathrm{~g} / \mathrm{dL}$ (reference range: $72-166 \mathrm{~g} / \mathrm{dL}$ ) \\
Serum ceruloplasmin & $0.03 \mathrm{~g} / \mathrm{L}$ (reference range: $0.15-0.62 \mathrm{~g} / \mathrm{L}$ ) \\
Blood amino acid chromatography & Normal \\
Amino acid acyl carnitine & Normal \\
\hline
\end{tabular}

Menkes disease holds an estimated prevalence of 1 in 8,664 live male births [4]. It is among a spectrum of disorders arising from defective ATP7A, the critical X-linked gene encoding copper transporting ATPase. The fundamental disease process is of a preserved cellular copper uptake but aberrancy in transportation and subsequent utilization by its dependent enzymes $[1,3,5]$. Key examples of the latter include cytochrome $c$ oxidase required for electron transport, superoxide dismutase responsible for free radical detoxification, dopamine beta-hydroxylase needed for catecholamine production, lysyl oxidase required for cross-linking of elastin and collagen, and peptidyl-glycine alpha amidating monooxygenase needed for bioactivation of peptide hormones [3].

There has been a demonstrated parallel between the degree of residual ATP7A activity and disease phenotype, which would explain the spectrum of disease presentation from mild occipital motor horn syndrome to lethal classical Menkes disease [6, 7]. Recent reports have even demonstrated disease phenotype in carrier females (in addition to the rare occasions of sex chromosome aneuploidy or X-autosome translocation) [2]. Classic Menkes disease typically manifests at 6-8 weeks of age with progressive loss of developmental milestones, new onset of seizures, hypotonia, failure to thrive, and the concomitant onset of characteristic hair shaft anomalies (sparse, coarse, brittle, short, twisted hair with a microscopic picture of pili torti, monilethrix, and trichorrhexis nodosa) [8-16].

Diagnosis is hinged upon characteristic clinical features; lab findings of low serum copper and ceruloplasmin; EEG features of focal spikes with subsequent secondary generalization [17]; MRI brain evidence of vascular anomalies, myelination delays, and neurodegenerative changes [18-20]; as well as absolute confirmation via genetic analysis. Disease prognosis remains poor, with most children dying by 3 years of age after respiratory tract infections. 
Therapeutic modalities are limited to parenteral administration of copper histidine, which can ameliorate neurologic disease but cannot reverse the connective tissue manifestations [1]. Major confounding factors include timing of replacement therapy (negligible response if treatment delayed beyond) and ease of access to copper histidine therapy (both financially and geographically). Prenatal diagnosis is of utmost importance once a proband is diagnosed, as that would aid in early identification in the following offspring $[1,13]$.

\section{Conclusion}

Menkes disease is a lethal neurodegenerative condition with onset in a previously well infant. Diagnosis hinges on astute clinical observation - the combination of pathognomonic hair shaft changes and neurodegeneration in a well-child, should spark confirmation via investigations as available. Treatment is with parenteral copper histidine administration at the earliest time possible, along with general supportive management.

\section{Statement of Ethics}

Ethical approval was not required for this study in accordance with the Dubai Health Authority Research Committee policies. Written informed consent was obtained from the patient's parents for publishing the case report including any accompanying materials.

\section{Conflict of Interest Statement}

The authors have no conflicts of interest to declare.

\section{Funding Sources}

The authors have no funding sources to declare.

\section{Author Contributions}

All authors have contributed to writing, researching, and finalizing the case report.

\section{Data Availability Statement}

All data generated or analyzed during this case are included in this article. Further enquiries can be directed to the corresponding author.

\section{References}

1 Kaler SG, DiStasio AT. ATP7A-related copper transport disorders. In: Adam MP, Ardinger $\mathrm{HH}$, Pagon RA, Wallace SE, Bean LJH, Mirzaa G, et al., editors. GeneReviews ${ }^{\circledR}$. Seattle: University of Washington; 19932021. p. 1993-2021 [2003 May 9, updated 2021 Apr 15].

2 Desai V, Donsante A, Swoboda KJ, Martensen M, Thompson J, Kaler SG. Favorably skewed X-inactivation accounts for neurological sparing in female carriers of Menkes disease. Clin Genet. 2011 Feb;79(2):176-82.

3 Tümer Z, Horn N. Menkes disease: recent advances and new aspects. J Med Genet. 1997 Apr;34(4):265-74.

4 Kaler SG, Ferreira CR, Yam LS. Estimated birth prevalence of Menkes disease and ATP7 Arelated disorders based on the Genome Aggregation Database (gnomAD). Mol Genet Metab Rep. 2020 Sep;24:100602.

5 Kodama H, Fujisawa C, Bhadhprasit W. Inherited copper transport disorders: biochemical mechanisms, diagnosis, and treatment. Curr Drug Metab. 2012 Mar;13(3):237-50.

6 Kaler SG, Holmes CSMT, Goldstein DS, Tang J, Godwin SC, Donsante A, et al. Neonatal diagnosis and treatment of Menkes disease. $\mathrm{N}$ Engl J Med. 2008;358:605-14.
7 León-García G, Santana A, Villegas-Sepúlveda N, Pérez-González C, Henrríquez-Esquíroz JM, de León-García C, et al. The T1048I mutation in ATP7A gene causes an unusual Menkes disease presentation. BMC Pediatrics. 2012 Sep 19;12(1):150.

8 Fister P, Rakus J, Primec ZR, Strazisar BG. Menkes kinky hair disease (Menkes syndrome). A case report. Acta Dermatovenerol Alp Pannonica Adriat. 2006 Sep;15(3):12630.

9 Verma A, Menghani K, Sureka B, Mittal A, Bhatt S. Menkes kinky hair disease. Indian Pediatr. 2016;53:86.

10 Hussain AA. Menkes syndrome: a case report. J Med Sci Clin Res. 2018 Apr 30;6(4).

11 Bocopoulou F, Henderson L, Philip SG. Menkes disease mimicking non-accidental injury. Arch Dis Child. 2006;91(11):919.

12 Datta AK, Ghosh T, Nayak K, Ghosh M. Menkes kinky hair disease: a case report. Cases J. 2008 Sep 18;1(1):158.

13 Costa LS, Pegler SP, Lellis RF, Krebs VLJ, Robertson S, Morgan T, et al. Menkes disease: importance of diagnosis with molecular analysis in the neonatal period. Rev Assoc Med Bras. 2015 Sep;61(5):407-10.
14 Agertt F, Crippa ACS, Lorenzoni PJ, Scola RH, Bruck I, de Paola L, et al. "Menkes disease". Arq Neuropsiquiatr. 2007;65(1): 157160.

15 Walker FA, Goho C, Schanzer RB. Menkes disease: report of two cases. ASDC J Dent Child. 2002 Jan;69(1):70.

16 Mohan A, Singh S, Gupta A, Pandey A. Menkes disease: case report. Pigment Int. 2018;5(1):43-6.

17 Friedman E, Harden A, Koivikko M, Pampiglione G. Menkes' disease: neurophysiological aspects. J Neurol Neurosurg Psychiatry. 1978;41(6):505-10.

18 Manara R, D’Agata L, Rocco MC, Cusmai R, Freri E, Pinelli L, et al. Neuroimaging changes in Menkes disease, part 1. Am J Neuroradiol. 2017 Oct;38(10):1850-7.

19 Manara R, Rocco MC, D’Agata L, Cusmai R, Freri E, Giordano L, et al. Neuroimaging changes in Menkes disease, part 2. Am J Neuroradiol. 2017 Oct;38(10):1858-65.

20 Rangarh P, Kohli N. New Menkes disease findings from King George's Medical University described (neuroimaging findings in Menkes disease: a rare neurodegenerative disorder). Obes Fitness Wellness Week. 2018 Jun 9:3351. 